\title{
Recognition and Molecular Discrimination of Severe and Mild PVY Variants of Potato virus $Y$ in Potato in New Brunswick, Canada
}

\author{
Bihua Nie, Potato Research Centre, Agriculture and Agri-Food Canada (PRC-AAFC), Fredericton, New Brunswick E3B 4Z7, \\ Canada, and National Center for Vegetable Improvement (Central China), MOE Key Laboratory of Horticultural Plant Biology, \\ Hubei Provincial Research Center of Potato Engineering and Technology, Huazhong Agricultural University, Wuhan 430070, China; \\ Mathuresh Singh, Agricultural Certification Services, New Brunswick E3B 8B7, Canada; Andrew Sullivan, Plant Propagation \\ Centre, New Brunswick Department of Agriculture and Aquaculture, Fredericton, New Brunswick E3B 5H1, Canada; Rudra P. \\ Singh, retired, PRC-AAFC; Conghua Xie, National Center for Vegetable Improvement (Central China), MOE Key Laboratory of \\ Horticultural Plant Biology, Hubei Provincial Research Center of Potato Engineering and Technology, Huazhong Agricultural \\ University; and Xianzhou Nie, PRC-AAFC
}

\begin{abstract}
Nie, B., Singh, M., Sullivan, A., Singh, R. P., Xie, C., and Nie, X. 2011. Recognition and molecular discrimination of severe and mild PVYO variants of Potato virus $Y$ in potato in New Brunswick, Canada. Plant Dis. 95:113-119.

A field isolate of Potato virus $Y$ (PVY) was collected in New Brunswick, Canada in 2007 due to unusual symptoms observed on different potato cultivars. To unveil the PVY strain identity, tobacco and potato bioassays, $\mathrm{PVY}^{\mathrm{O}}$ and $\mathrm{PVY}^{\mathrm{N}}$-specific antibody-based enzyme-linked immunosorbent assays, and reverse-transcription polymerase chain reaction (PCR)-based genotyping were carried out. All the assays demonstrated that the isolate, designated as $\mathrm{PVY}{ }^{\mathrm{O}}$-FL in this study, belonged to the $\mathrm{PVY}^{\mathrm{O}}$ strain group. Greenhouse tests with the potato cvs. FL 1533 and Jemseg confirmed the severe nature of infection by $\mathrm{PVY}^{\mathrm{O}}-\mathrm{FL}$. The complete genome sequences of PVY ${ }^{\mathrm{O}}-\mathrm{FL}$ and $\mathrm{PVY}^{\mathrm{O}_{-}}$ $\mathrm{RB}$, the latter a mild $\mathrm{PVYO}$ isolate, were determined. BLAST analysis revealed that the two isolates shared 97 and $98 \%$ sequence identities at the nucleotide and polyprotein levels, respectively. Further BLAST analysis unveiled that $\mathrm{PVY}{ }^{\mathrm{O}}$-FL shared $99.7 \%$ nucleotide sequence identity with $\mathrm{PVY}^{\mathrm{O}}-\mathrm{Oz}$, an isolate reported in New York, United States,

whereas the $\mathrm{PVY}-\mathrm{RB}$ isolate shared $99.2 \%$ sequence identity with $\mathrm{PVY}^{\mathrm{O}}-139$, a PVYO isolate reported in New Brunswick, Canada. A phylogenetic tree of available, full-length sequences of PVY isolates demonstrated two subgroups within the $\mathrm{PVY}^{\mathrm{O}}$ branch, one clustered with $\mathrm{PVY}^{\mathrm{O}}-\mathrm{RB}$ and the other with $\mathrm{PVY} \mathrm{O}^{\mathrm{O}} \mathrm{FL}$. Group-specific sense primers for differentiation of the two subgroups were developed and evaluated. A limited survey of potato tubers collected from a field plot at the Potato Research Centre, Agriculture and Agri-Food Canada, using the newly developed PCR primers, indicated that 65.3 and $2.4 \%$ of the $\mathrm{PVY}^{\mathrm{O}}$-positive tubers were infected with $\mathrm{PVY}^{\mathrm{O}}$ isolates belonging to the $\mathrm{PVY} \mathrm{O}^{\mathrm{O}} \mathrm{FL}$ and $\mathrm{PVY} \mathrm{Y}^{\mathrm{O}} \mathrm{RB}$ subgroups, respectively. Assessment of the pathogenicity of three representative isolates from each subgroup on the potato cv. Jemseg demonstrated that severe and mild symptoms were induced by the $\mathrm{PVY}^{\mathrm{O}}$-FL-like and $\mathrm{PVY}^{\mathrm{O}}-\mathrm{RB}$-like isolates, respectively.
\end{abstract}

Potato virus Y (PVY, genus Potyvirus, family Potyviridae) is one of the most economically important viruses of the potato crop worldwide (29). The virus possesses a single-stranded, positivesense RNA genome of approximately $9.7 \mathrm{~kb}$, with one open reading frame encoding a single polyprotein (24). PVY induces various foliar symptoms in potato plants ranging from mosaic to leaf-drop streaks and stunting, depending on cultivars and virus strains, and can cause up to $80 \%$ yield reduction $(8,22,34)$.

Potato growers across North America have noticed an increase in PVY incidence in their potato crops in the last 10 years $(5,21,23,28)$. The increase in PVY levels and the emergence of different strains of PVY, including the tobacco veinal necrosis strain $\left(\mathrm{PVY}^{\mathrm{N}}\right)$, the recombinant $\mathrm{N}: \mathrm{O}$ strain $\left(\mathrm{PVY}^{\mathrm{N}: \mathrm{O}}\right)$, and the po-

\section{Corresponding author: X. Nie, E-mail: xianzhou.nie@agr.gc.ca}

The nucleotide sequence data reported in this paper have been submitted to GenBank and have been assigned the accession numbers HM367075 and HM367076.

* The $\boldsymbol{e}$-Xtra logo stands for "electronic extra" and indicates that two supplementary figures and one supplementary table not included in the print edition are available online.

Accepted for publication 9 October 2010.

doi:10.1094/PDIS-04-10-0257

This article is in the public domain and not copyrightable. It may be freely reprinted with customary crediting of the source. The American Phytopathological Society, 2011. tato tuber ringspot necrosis strain ( $\mathrm{PV} \mathrm{Y}^{\mathrm{NTN}}$ ), in many potato-growing areas in North America are of particular concern $(5,10$, $11,23,28)$. In New Brunswick, Canada, the common or ordinary strain $\left(\mathrm{PVY}^{\mathrm{O}}\right)$ is known to be present (26). Although various symptoms may be induced by $\mathrm{PVY}^{\mathrm{O}}$, typical symptoms are normally observed on plants infected with this strain. For instance, necrotic lesions and veinal necrosis are typical symptoms caused by current season infection of the cv. Jemseg with PVY ${ }^{\mathrm{O}}(27)$, whereas mosaic is the most common symptom caused by $\mathrm{PVY}^{\mathrm{O}}$ infection of cultivars such as Russet Burbank, Atlantic, and Shepody $(15,31,33)$.

During the summer of 2007, seed potato inspectors from the Canadian Food Inspection Agency (CFIA) noticed some unusually severe PVY-like symptoms in growers' fields of different potato cultivars in the Grand Falls area of New Brunswick, Canada. The symptoms consisted of mild mosaic, chlorosis, and necrotic lesions on leaflets, followed by severe veinal necrosis and dying of entire infected branches of several potato cultivars, including FL 1533, FL 1579, Atlantic, and Goldrush. The atypical PVY-like symptoms in these cultivars led the inspectors to suspect they might be caused by a newly emerged PVY isolate in New Brunswick, thus prompting studies to unveil the identity and properties of the causal agent. In this report, we present the identification of an isolate of $\mathrm{PVY}^{\mathrm{O}}$ from New Brunswick, Canada that causes severe symptoms on potato, and the pathological and molecular characterization of this isolate as well as a $\mathrm{PVY}^{\mathrm{O}}$ isolate that causes mild symptoms on potato and that is known to occur in this province. A reverse-transcription polymerase chain reaction (RT-PCR)-based assay for discrimination of these $\mathrm{PVY}^{\mathrm{O}}$ variant groups was also developed and evaluated. To our knowledge, this is the first report describing the 
relationship between the $\mathrm{PVY}^{\mathrm{O}}$ genome sequence and symptom severity in potato plants, and differentiation of $\mathrm{PVY}^{\mathrm{O}}$ variant groups.

\section{Materials and Methods}

Viral samples. Potato leaf samples with suspected symptoms of viral infection were collected in the 2007 growing season from fields in Grand Falls, New Brunswick, Canada. One field planted with each of the cvs. FL 1533, FL 1579, Goldrush, and Russet Burbank was sampled from commercial potato-seed-producing farms. The foliar symptoms on cvs. FL 1533, FL 1579, and Goldrush included chlorosis and necrotic lesions on leaflets, followed by severe veinal necrosis and early dying of entire symptomatic branches; on cv. Russet Burbank, symptoms included severe mosaic on the leaves. Four fully expanded, symptomatic leaves from a diseased plant of each cultivar and three stems from FL 1533 were brought to the Agricultural Certification Services (ACS), Fredericton, New Brunswick, Canada, and the Potato Research Centre, Agriculture and Agri-Food Canada (PRC-AAFC), Fredericton, New Brunswick, Canada, for further serological (ACS), biological (ACS and PRC-AAFC), and molecular identification (PRC-AAFC) of the causal agent. The three stems from FL 1533 were grafted onto healthy potato plantlets to maintain the original virus culture in the greenhouse. Following preliminary identification, one representative isolate (the isolate from the FL 1533, designated as $\mathrm{PVY}^{\mathrm{O}}$-FL) of the virus detected in these samples was selected for further biological and molecular characterization. In addition, greenhouse-maintained PVY isolates of $\mathrm{PVY}^{\mathrm{N}}-\mathrm{Jg}, \mathrm{PVY}^{\mathrm{NTN}}-\mathrm{Sl}$, $\mathrm{PVY}^{\mathrm{N}: \mathrm{O}}-\mathrm{Mb} 58$, and $\mathrm{PVY} \mathrm{O}^{\mathrm{O}}-\mathrm{RB}$ (17-20) were used for comparison with these New Brunswick field isolates.

Enzyme-linked immunosorbent assay. Samples of potato leaves and stems were first tested by enzyme-linked immunosorbent assay (ELISA) with virus-specific antibodies for common viruses of potato, including PVY, Potato virus $S$ (PVS), Potato virus $A$ (PVA), Potato virus $M$ (PVM), Potato virus $X$ (PVX), and Potato leafroll virus (PLRV) (Phyto Diagnostics, North Saanich, BC, Canada), as described previously (28). After determining that PVY was the only virus of the six tested that was present in all of the samples, the same samples were tested further using PVY antibodies for specific PVY serotypes. The PVY-Poly and 4C3 antibodies used are strain-nonspecific and capable of detecting all PVY strains, whereas MAb2 is $\mathrm{PVY}^{\mathrm{O}}$ serotype specific and 1F5 is $\mathrm{PVY}^{\mathrm{N}}$ serotype specific (6).

Symptom observation in potato and tobacco plants. The common tobacco (Nicotiana tabacum L.) cv. Samsun and potato (Solanum tuberosum L.) cvs. FL 1533, FL 1879, FL 1207, FL 1867, Jemseg, and Yukon Gold were used to characterize the plant pathological properties of the New Brunswick PVY isolates. Four tobacco seedlings and four virus-free potato plantlets of each cultivar were mechanically inoculated with PVY isolates, as described previously (28), and grown in a greenhouse with $12 \mathrm{~h}$ of light/day $\left(90 \mu \mathrm{m}^{2} / \mathrm{s}\right)$ at 18 to $22^{\circ} \mathrm{C}$. Tobacco seedlings and potato plantlets treated with buffer served as the healthy (negative) control treatments, and Russet Burbank infected with $\mathrm{PVY}^{\mathrm{O}}$ (PVY $\left.{ }^{\mathrm{O}}-\mathrm{RB}\right)$ (17) as the positive control treatment. The development of necrosis on inoculated leaves (local lesions) and systemic mosaic or necrosis of branches and whole plants was recorded weekly for 13 weeks after inoculation. After harvest of the potato tubers, the tubers were examined for symptoms of potato tuber necrotic ringspot (PTNR) (18), then stored at room temperature in the dark for 3 months and examined monthly for PTNR symptoms. The experiment was repeated two times in two subsequent years.

RT-PCR-based genotyping. RT-PCR-based PVY genotyping was carried out as described previously $(9,20)$. Two steps were involved: (i) $\mathrm{P} 1$ gene-based $\mathrm{PVY} / \mathrm{PVY}^{\mathrm{N} / \mathrm{N}: \mathrm{O} / \mathrm{NTN}}$ determination (17) and (ii) recombinant joint (RJ)-based $\mathrm{PVY}^{\mathrm{N}} / \mathrm{PVY}^{\mathrm{N}: \mathrm{O}} / \mathrm{Eu}-$ $\mathrm{PVY}^{\mathrm{NTN}}$ determination (19). Another format of multiplex RT-PCR developed by Lorenzen et al. (14) was used to verify results of the above genotyping assays. In addition, a new coat protein (CP)gene-based method of $\mathrm{PVY}^{\mathrm{O}}$ isolate group differentiation was developed in this study (see Results). The P1 gene-based RT-PCR assay can differentiate $\mathrm{PVY}^{\mathrm{O}}$ from $\mathrm{PVY}^{\mathrm{N} / \mathrm{N}: \mathrm{O} / \mathrm{NTN}}$ (17), and the RJbased RT-PCR assay can determine the common recombinant events found in PVY ${ }^{\mathrm{N}: \mathrm{O}}$ and PVY $\mathrm{PTN}^{\mathrm{NT}}$ (19). The PCR assay was performed on a PTC-200 Thermocycler (MJ Research, Watertown, MA). The amplification products $(10 \mu \mathrm{l})$ were separated by electrophoresis on $1.2 \%$ agarose gels containing $1 \times$ GelRed (Biotium Inc., Hayward, CA) and photographed under UV light with a FluorChem Imaging System (Alpha Innotech, San Leandro, CA).

Complementary DNA cloning and sequencing. For the purpose of cloning and sequencing the complete genome of PVY, total RNA was isolated from leaves of PVY ${ }^{\mathrm{O}}$-RB- or PVY ${ }^{\mathrm{O}}$-FL-infected potato or tobacco plants, as described above, using the $\mathrm{LiCl}$ procedure (16). RT-PCR-based cloning was performed using nine sets of primers that span the entire genome of PVY (for primer sequences, polarities and approximate locations, see 18). Each primer pair was projected to result in a DNA fragment of 1.0 to $1.3 \mathrm{~kb}$, overlapping with adjacent fragments by approximately $100 \mathrm{bp}$ at each end. For the $\mathrm{PVY}^{\mathrm{O}}-\mathrm{RB}$ isolate, all primer pairs successfully amplified the target fragments whereas, for the $\mathrm{PVY}^{\mathrm{O}}$-FL isolate, three primer pairs (nos. 3, 6, and 7) (18) failed to generate visible fragments. Upon cloning and sequencing the amplicons, three primer pairs (5'ATTGCCAAGCAGGGTTATTG3'/5'GCTCCATGCAGACAAT CTCA3', 5'TCGTGGACTGTGATGCATTT3'/5'ATGCGACCA TCATTTCAGTG3', and 5'GAAATGCAAGCCTTGGGTAG3'/ 5'CCCTATTGATGGCTTCCTCA3') were designed to amplify the missing fragments of PVYO ${ }^{\mathrm{O}}$-FL. In addition, the $5^{\prime}$ rapid amplification of cDNA ends system (version 2.0; Invitrogen, Carlsbad, CA) was employed to determine or verify the $5^{\prime}$-end nucleotides of both isolates according to the manufacturer's instructions.

The details of the RT-PCR assay conditions were described previously (20). The putative PVY fragments amplified by the various primers were separated on a $1.2 \%$ agarose gel and extracted from the gel using a DNA extraction kit (Qiagen, Valencia, CA). Purified fragments were cloned into a pDrive Cloning Vector (Qiagen) according to the manufacturer's instructions. Two cDNA clones of each fragment were sent to Robarts Research Institute (London, Ontario, Canada) for forward and reverse sequencing using the T7 promoter and SP6 promoter primers, respectively (for more information, see the manufacturer's instructions on pDrive Cloning Vector; Qiagen). Each isolate was fully sequenced twice, from RNA of infected tobacco leaves and from RNA of infected potato leaves of cv. Jemseg, with identical results. Sequence identities and alignments of these isolates with various potato virus species were analyzed using BLAST (http://www.ncbi.nlm.nih.gov/ BLAST) and ClustalW (http://www.ebi.ac.uk/Tools/clustalw2/ index.html). MEGA version 4.2 (32) was employed to analyze the phylogeny of PVY isolates at the complete genome sequence level.

\section{Results}

Serological-, molecular-, and biological-based assays of the field virus samples. Except for PVY, ELISAs gave negative readings for each potato virus evaluated (data not shown), indicating that PVY was the only virus of the six tested that was present in these New Brunswick field samples of potato foliage, and suggesting that the symptoms on all four potato cultivars were caused by PVY. As expected, positive ELISA readings were recorded for all potato foliar samples with the strain-nonspecific polyclonal (PVYPoly) and monoclonal (4C3) antibodies (Table 1). For the strainspecific antibodies, all the samples gave positive ELISA readings to the $\mathrm{PVY}^{\mathrm{O}}$-specific antibody MAb2 but not to the $\mathrm{PVY}^{\mathrm{N}}$-specific antibody 1F5, except for a PVY $\mathrm{PV}^{\mathrm{O}}+\mathrm{PVY}^{\mathrm{N}}$-infected Russet Burbank leaf sample (Table 1), demonstrating that the PVY strains in these plant samples possessed a $\mathrm{PVY}^{\mathrm{O}}$-serotype.

It has been well established that $\mathrm{PVY}^{\mathrm{N}: \mathrm{O}}, \mathrm{PVY}^{\mathrm{NTN}-\mathrm{HN} 2}$, and $\mathrm{PVY}^{\mathrm{NTN}-\mathrm{NW}}$ isolates possess a $\mathrm{PVY}^{\mathrm{O}}$-serotype but a PVY ${ }^{\mathrm{N}}$-pathotype in tobacco and a PVY ${ }^{\mathrm{N}}$-type $\mathrm{P} 1$ gene in the genome $(4,9,20)$. The PCR assay results demonstrated that the New Brunswick field isolates of PVY possessed a PVY ${ }^{\mathrm{O}}$-type P1 gene and were free of known RJs (Supplementary Figure 1). The tobacco-based bioassay indicated that the New Brunswick PVY isolates as well as the 
PVYO ${ }^{\mathrm{O}}$ RB isolate induced mosaic symptoms on tobacco leaves, whereas $\mathrm{PVY}^{\mathrm{N}}, \mathrm{PVY}^{\mathrm{N}: \mathrm{O}}$, and $\mathrm{PVY}^{\mathrm{NTN}}$ isolates induced severe veinal, petiole, and stem necrosis, illustrating the $P V Y^{\mathrm{O}}$ pathotype of the New Brunswick field isolates. No symptoms were observed on the negative control tobacco plants treated with buffer. Except for PVY ${ }^{\mathrm{NTN}}$, none of the isolates induced PTNR symptoms in tubers of cv. Yukon Gold, which is highly susceptible to PTNR $(9,23)$. Based on these results, it was concluded that $P V Y^{\mathrm{O}}$ was the causal agent of the unusually severe PVY-like symptoms observed on potato cultivars in New Brunswick, Canada. One representative isolate recovered from cv. FL 1533 and designated as PVY ${ }^{\mathrm{O}}$-FL was selected for further characterization.

Sequence characterization of PVY ${ }^{\mathrm{O}}$-FL and PVY ${ }^{\mathrm{o}}$-RB. Prior to cloning and sequencing, pathogenicity of a representative isolate of each of $\mathrm{PVY}{ }^{\mathrm{O}}$-FL and $\mathrm{PVY} \mathrm{Y}^{\mathrm{O}}-\mathrm{RB}$ (17) was again confirmed on potato and tobacco plants in a greenhouse. $\mathrm{PVY}{ }^{\mathrm{O}}$-FL induced more severe symptoms than $\mathrm{PVY}^{\mathrm{O}}-\mathrm{RB}$ on all the cultivars tested, including FL 1533, FL 1879, FL 1207, FL 1867, and Jemseg (Fig. 1; for cvs. FL 1879, FL 1207, and FL 1867, data not shown). For Jemseg, more local and systemic lesions were observed on the PVY ${ }^{\mathrm{O}}$-FL-

Table 1. Enzyme-linked-immunosorbent assay (ELISA) results for potato leaves and stems sampled from New Brunswick, Canada in 2007 and tested using various Potato virus $Y$ (PVY) antibodies

\begin{tabular}{lcccc}
\hline & & \multicolumn{2}{c}{ ELISA $\left(\right.$ OD $\left._{\mathbf{4 0 5}}\right)(\text { mean } \pm \text { standard deviation })^{\mathbf{a}}$} \\
\cline { 2 - 5 } Potato cultivar and tissue tested & PVY-Poly & $\mathbf{4 C 3}$ & MAb2 & $\mathbf{1 F 5}$ \\
\hline FL 1533 leaf & $\mathbf{1 . 0 6 5} \pm \mathbf{0 . 0 5 5}$ & $\mathbf{0 . 7 7 0} \pm \mathbf{0 . 0 2 0}$ & $\mathbf{2 . 1 6 0} \pm \mathbf{0 . 0 5 0}$ & $0.004 \pm 0.002$ \\
FL 1533 stem & $\mathbf{0 . 5 8 0} \pm \mathbf{0 . 0 2 0}$ & $\mathbf{0 . 2 5 5} \pm \mathbf{0 . 0 2 5}$ & $\mathbf{0 . 6 0 5} \pm \mathbf{0 . 0 1 5}$ & $0.002 \pm 0.002$ \\
FL 1579 leaf & $\mathbf{2 . 2 9 3} \pm \mathbf{0 . 0 8 0}$ & $\mathbf{1 . 6 8 3} \pm \mathbf{0 . 0 2 4}$ & $\mathbf{2 . 8 2 0} \pm \mathbf{0 . 0 1 4}$ & $0.004 \pm 0.002$ \\
Goldrush leaf & $\mathbf{1 . 8 6 7} \pm \mathbf{0 . 0 0 9}$ & $\mathbf{0 . 8 9 0} \pm \mathbf{0 . 0 1 4}$ & $\mathbf{2 . 4 6 0} \pm \mathbf{0 . 0 5 7}$ & $0.004 \pm 0.002$ \\
Russet Burbank leaf & $\mathbf{1 . 3 2 3} \pm \mathbf{0 . 0 3 8}$ & $\mathbf{0 . 7 3 7} \pm \mathbf{0 . 0 1 9}$ & $\mathbf{1 . 6 4 3} \pm \mathbf{0 . 0 1 9}$ & $0.004 \pm 0.002$ \\
PVY O PVY $^{\mathrm{N}}$-infected Russet Burbank leaf & $\mathbf{1 . 5 5 7} \pm \mathbf{0 . 0 2 3}$ & $\mathbf{0 . 5 7 3} \pm \mathbf{0 . 0 0 5}$ & $\mathbf{1 . 7 6 0} \pm \mathbf{0 . 0 2 8}$ & $\mathbf{1 . 2 3 0} \pm \mathbf{0 . 0 1 4}$ \\
Virus-free Russet Burbank leaf & $0.001 \pm 0.001$ & $0.001 \pm 0.001$ & $0.002 \pm 0.002$ & $0.001 \pm 0.001$ \\
\hline
\end{tabular}

a ELISAs were completed using various antibodies: PVY-Poly = polyclonal antibody that reacts with all known strains of PVY; and 4C3, MAb2, and 1F5 = monoclonal antibodies that react with all known strains, PVYO strains, and PVYN strains, respectively. $\mathrm{OD}_{405}=$ optical density measured at $405 \mathrm{~nm}$. Each value represents the mean \pm standard deviation of four separate leaves or stems from the same plant assayed by ELISA (except three for FL 1533 stem). Numbers in bold represent ELISA-positive values for that assay. Samples were considered positive when the OD \pm was $\geq 0.100$ and four times greater than that of the negative (healthy) control samples (28).

\section{FL 1533}

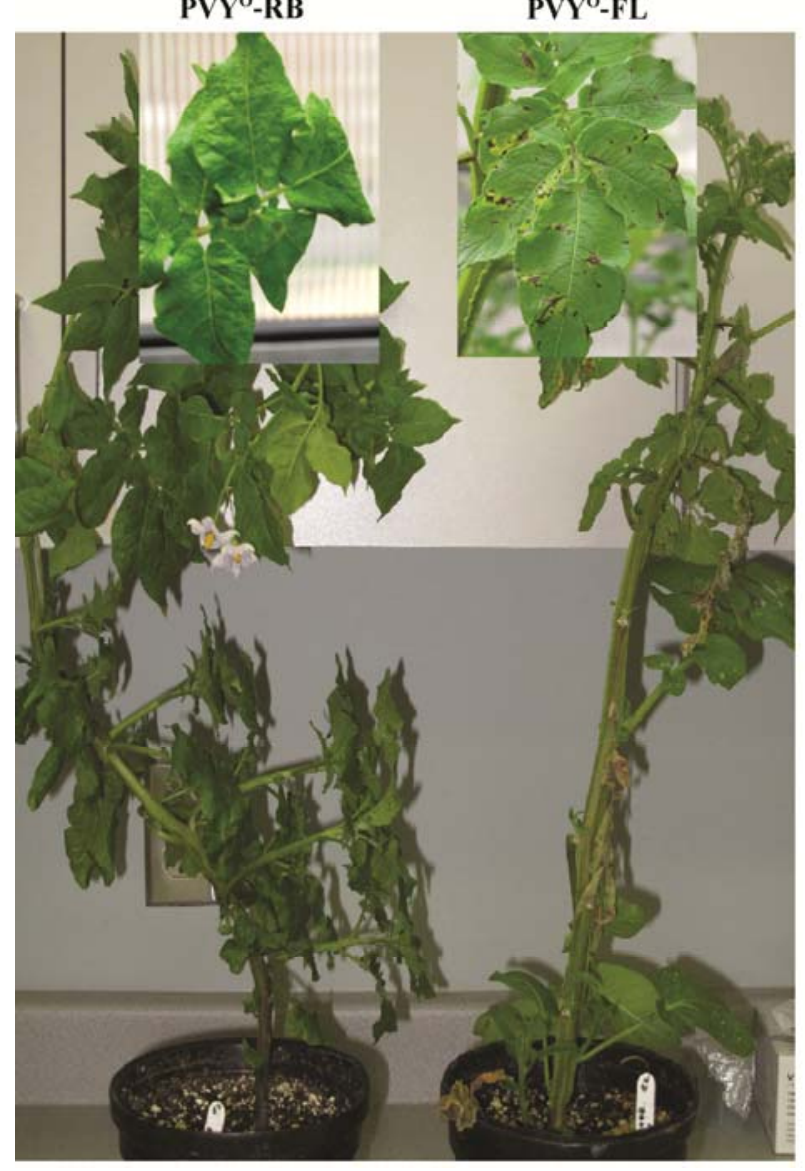

Inoculated leaf (8 dpi)

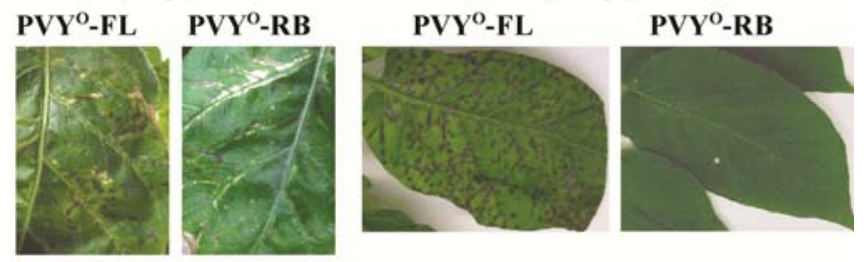

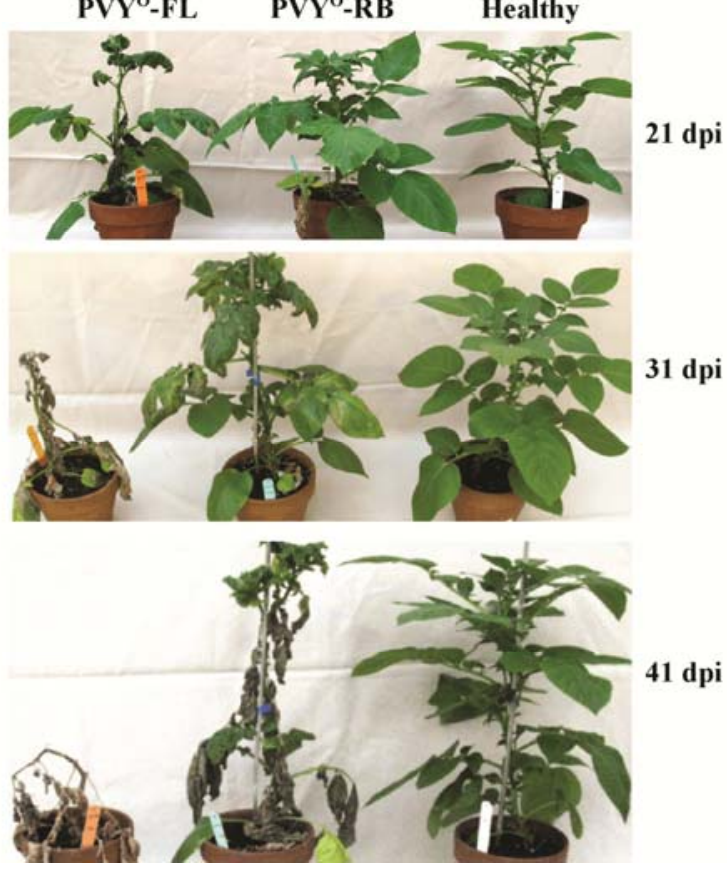

Fig. 1. Symptoms induced by Potato virus $Y$ (PVY) isolates PVYO-FL and PVYO-RB on potato cvs. FL 1533 and Jemseg. Virus-free plantlets of potato cvs. FL 1533 and Jemseg were mechanically inoculated with PVYO-FL or PVYO-RB as described by Singh et al. (28). Symptoms were monitored for up to 3 months after inoculation. The experiments with FL 1533 and Jemseg were carried out in greenhouses at the Agricultural Certification Services and the Potato Research Centre, Agriculture and Agri-Food Canada, respectively, in New Brunswick, Canada. Photos of the FL 1533 plants were taken 35 days post inoculation (dpi). Photos of Jemseg plants were taken 21, 31, and $41 \mathrm{dpi}$; for inoculated leaves and noninoculated leaves located above the inoculated leaves, the photos were taken 8 and 14 dpi, respectively. 
inoculated plants than on the PVY ${ }^{\mathrm{O}}$-RB-inoculated plants (Fig. 1, Jemseg), although this difference was not quantified statistically. Inoculation with $\mathrm{PVY}^{\mathrm{O}}$-FL led to plant death 31 days post inoculation (dpi), whereas $\mathrm{PVY}^{\mathrm{O}}-\mathrm{RB}$ did not kill the plants even by 41 dpi (Fig. 1, Jemseg). These results demonstrated that $\mathrm{PVY}^{\mathrm{O}}$-FL is a variant of $\mathrm{PVY}^{\mathrm{O}}$ that causes severe symptoms, whereas $\mathrm{PVY}^{\mathrm{O}}-\mathrm{RB}$ is a variant of $\mathrm{PVY}^{\mathrm{O}}$ that causes mild symptoms (hereafter referred to as severe and mild variants, respectively). Both isolates induced similar mosaic symptoms on tobacco leaves (data not shown).
The genome size was 9,698 nucleotides, excluding poly(A), for both the PVYO $-\mathrm{FL}$ and $\mathrm{PVY}^{\mathrm{O}}-\mathrm{RB}$ New Brunswick isolates (Supplementary Table 1). The two isolates shared 97 and $98 \%$ sequence identities at nucleic acid and polyprotein levels, respectively. Comparison of the PVYO-FL sequence with sequences of other PVY isolates retrieved from GenBank demonstrated that PVY ${ }^{\mathrm{O}}$-FL shared approximately $99.7 \%$ sequence identity with $\mathrm{PVY}^{\mathrm{O}}-\mathrm{Oz}$ (accession number EF026074), a PVY ${ }^{\mathrm{O}}$ isolate reported in the northeastern United States (2), and $96 \%$ identity with PVY ${ }_{-}^{-}$ 139 (accession number U09509), a PVY ${ }^{\mathrm{O}}$ isolate reported in New

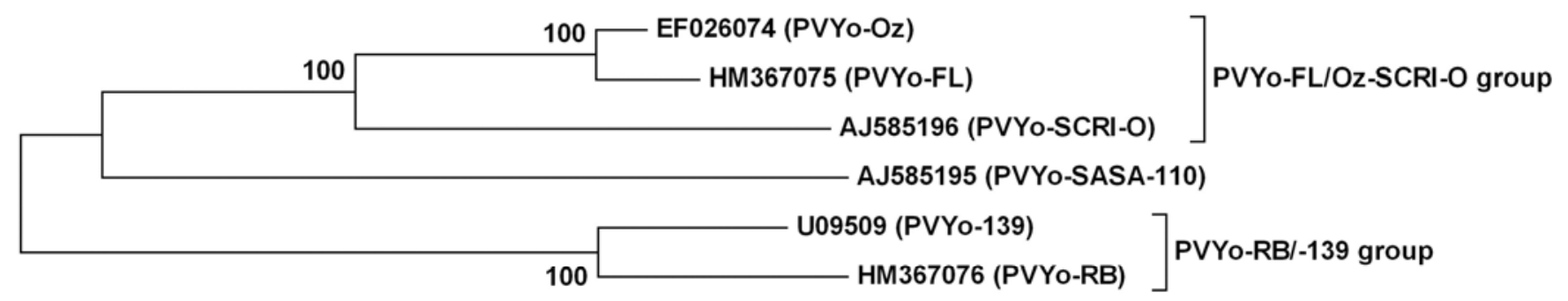

$\stackrel{\longmapsto}{0.002}$

Fig. 2. Phylogeny of isolates of the Potato virus $Y$ common strain (PVYO). Full-length sequences of $P V Y^{\circ}$ were used for phylogenetic analysis employing MEGA4 with the neighbor-joining method (32). The scale bar represents genetic distance. Numbers at the nodes indicate the percentage of replicate trees in which the associated taxa clustered together in the bootstrap test (1,000 replicates). The PVYO isolates and associated GenBank accession numbers are shown.

A
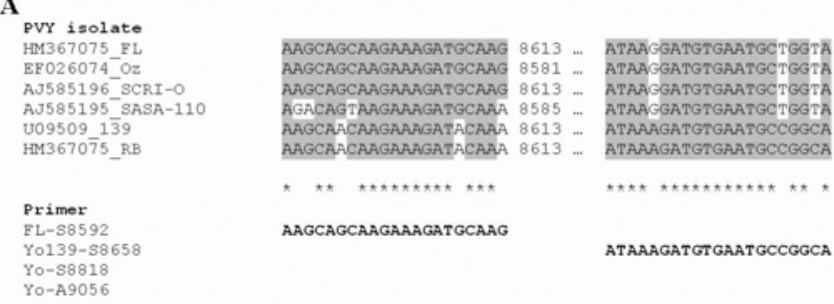

ATAAAGATGTGAATGCCGGCA
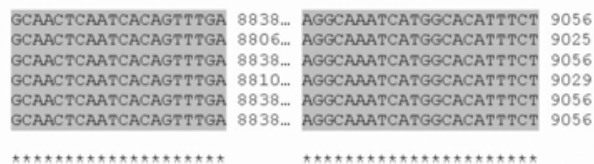

GCAACTCAATCACAGTTTGA

AGAAATGTGCCATGATTTGCCT

B

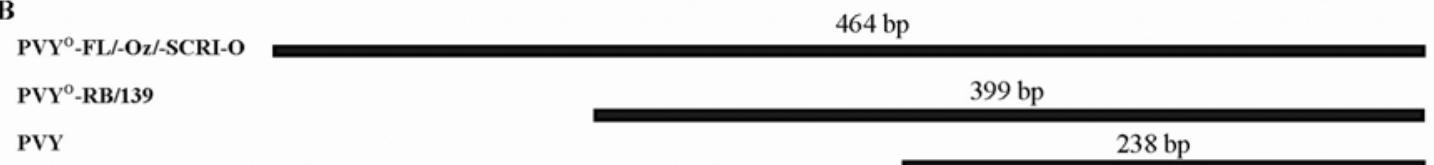

C

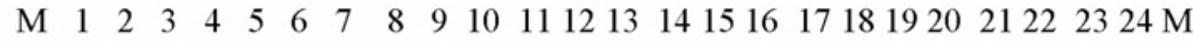

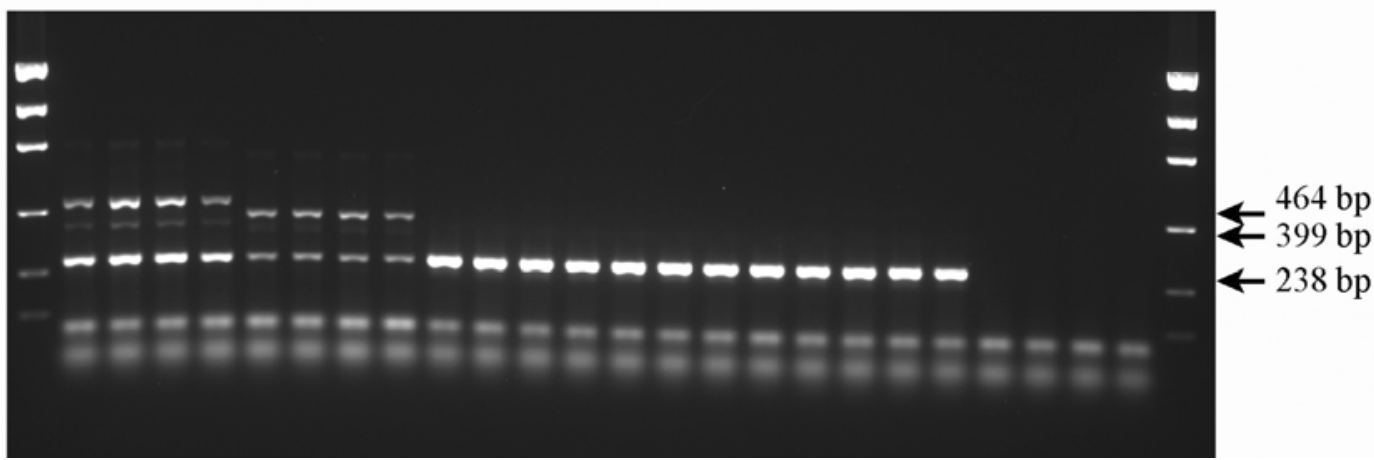

Fig. 3. Differentiation of isolates of the Potato virus $Y$ common strain ( $\left.P V Y^{\circ}\right)-F L$ and $P V Y^{O}-R B$ groups using reverse transcription-polymerase chain reaction (RT-PCR) assay. A, Alignment of sequences of PVYO isolates for designing PCR primers for differentiation of PVYO-FL and PVYO-RB isolates. Numbers in the alignment indicate the nucleotide locations in the input sequences reported by the GenBank accession number and PVY isolate name. The primers $\left(5^{\prime}\right.$ to $\left.3^{\prime}\right)$ were derived from the shaded nucleotides. FL-S8592 (targeting the PVYO-FL/-Oz/-SCRI-O group, i.e., PVYO-FL isolates), Y0139-S8658 (targeting the PVYO-RB/-139 group, i.e., PVYO-RB isolates), and YoS8818 (targeting all PVY isolates) are sense primers; and Yo-9056 (targeting all PVY isolates) is an antisense primer. B, Schematic diagram of PCR amplification products for differentiation of PVYO-FL/-Oz/-SCRI-O and PVYO-RB/-139 isolates. Target segments and resulting PCR products are illustrated. C, Multiplex RT-PCR assay results for differentiating PVYO-FL, PVYO-RB, and other PVY isolates. Lanes 1-4: PVYO-FL; lanes 5-8: PVYO-RB; lanes 9-12: PVYN:O-Mb58; lanes 13-16: PVYNTN-Sl; lanes 17-20: PVYN-Jg; lanes 21-24: healthy potato plant samples; $M=$ DNA ladder (from top to bottom: 2,000, 1,200, 800, 400, 200, and 100 bp). 
Brunswick (26). In contrast, $\mathrm{PVY}{ }^{\mathrm{O}}-\mathrm{RB}$ shared $99.2 \%$ sequence identity with $\mathrm{PVY} \mathrm{O}^{\mathrm{O}}-139$ and $97 \%$ identity with $\mathrm{PVY} \mathrm{Y}^{\mathrm{O}} \mathrm{-Oz}$.

A phylogenetic tree constructed using publicly available fulllength sequences of PVY isolates illustrated that several groups (namely, $\mathrm{PVY}^{\mathrm{C} / \text { non-potato }}, \mathrm{PVY}^{\mathrm{O}}$, nonrecombinant $\mathrm{PVY}^{\mathrm{N} / \mathrm{NTN}}$, $\mathrm{PVY}^{\mathrm{N}: \mathrm{O} / \mathrm{Wilga}}$, and recombinant $\mathrm{PVY}^{\mathrm{NTN}}$ ) were present. This is consistent with the results of previous studies $(9,10)$. Interestingly, two subgroups were observed in the $\mathrm{PVY}^{\mathrm{O}}$ branch, one including $\mathrm{PVY}^{\mathrm{O}}-139$, -RB, and -SASA-110 and the other including PVY ${ }_{-}$ $\mathrm{Oz},-\mathrm{FL}$, and -SCRI-O. An additional tree generated using only the $\mathrm{PVY}^{\mathrm{O}}$ full-length sequences showed consistent results with the above analysis, except for PVY ${ }^{\mathrm{O}}$-SASA-110 (Fig. 2). The latter, which loosely clustered with $\mathrm{PVY} \mathrm{O}^{\mathrm{O}} \mathrm{RB} / \mathrm{-139}$ in the tree shown in Supplementary Figure 2 and which grouped with PVY ${ }^{\mathrm{O}}-139$ in previous studies $(9,10)$, was placed between the $P V Y^{\mathrm{O}}-\mathrm{RB} /-139$ and PVYO ${ }^{\mathrm{O}}$-FL/-Oz/-SCRI-O groups (Fig. 2). This might represent a third $\mathrm{PVY}^{\mathrm{O}}$ variant type.

Differentiation of $\mathbf{P V Y}{ }^{\mathbf{O}}$ types. To differentiate $\mathrm{PVY} \mathrm{Y}^{\mathrm{O}}-\mathrm{FL}$ and $\mathrm{PVY}^{\mathrm{O}}$-RB isolates, the aligned nucleotide sequences were examined for regions suitable for designing primers capable of discriminating these two types of isolates. The $5^{\prime}$ proximal end of the $\mathrm{CP}$ gene demonstrated polymorphisms; therefore, primers were selected from this region. The sense primer FL-S8593 (5'-AAGCAG CAAGAAAGATGCAAG-3') matched with PVY ${ }^{\mathrm{O}}-\mathrm{FL}$, -Oz, and -SCRI-O; RB-S8658 (5'-ATAAAGATGTGAATGCCGGCA-3') matched with PVY ${ }^{\mathrm{O}}-139$ and $-\mathrm{RB}$; and S8819 (5'-GCAACT CAATCACAGTTTGA-3') and the antisense primer A9056 (5'AGAAATGTGCCATGATTTGCCT-3') matched with all isolates (Fig. 3A). A 464-bp amplicon was predicted to be produced by FLS8593/A9056 primers for PVY ${ }^{\mathrm{O}}$-FL, -Oz, and -SCRI-O isolates; a 399-bp fragment by RB-S8658/A9056 primers for PVY ${ }^{\mathrm{O}}-\mathrm{RB}$ and -139 isolates; and a 238-bp fragment by S8819/A9056 primers for all isolates, including PVYO-SASA-110 (Fig. 3B). Indeed, multiplex RT-PCR assays with all the primers resulted in amplification of the projected fragments for the respective isolates (Fig. 3C); a fragment at each of $464 \mathrm{bp}(\mathrm{PVY}-\mathrm{FL}$ isolate group specific) and 238 bp (common to all isolates) for $\mathrm{PVY}^{\mathrm{O}}$-FL (lanes 1 to 4 ); and at $399 \mathrm{bp}$ (PVY ${ }^{\mathrm{O}}$-RB isolate group specific) and $238 \mathrm{bp}$ (common to all isolates) for $\mathrm{PVY}^{\mathrm{O}}-\mathrm{RB}$; and one fragment of $238 \mathrm{bp}$ for all remaining PVY samples, including $\mathrm{PVY}^{\mathrm{N}: \mathrm{O}}$ (lanes 9 to 12 ), $\mathrm{PVY}^{\mathrm{NTN}}$ (lanes 13 to 16 ), and $\mathrm{PVY}^{\mathrm{N}}$ (lanes 17 to 20). The healthy potato samples did not produce any of these amplicons (Fig. 3C, lanes 21 to 24$)$.

The newly developed RT-PCR primers were further evaluated using potato tubers collected from a field plot at the PRC-AAFC, New Brunswick, Canada, from cultivars infected with unknown strains of PVY. The tubers were first screened using the P1 genebased RT-PCR assay for PVY ${ }^{\mathrm{O}}$ and PVY $\mathrm{PV}^{\mathrm{N} / \mathrm{N}: \mathrm{O} / \mathrm{NTN}}(17)$, and the $\mathrm{PVY}^{\mathrm{O}}$-positive samples were then subjected to $\mathrm{PVY}^{\mathrm{O}}$-FL/-FL-like and $\mathrm{PVY} \mathrm{O}^{\mathrm{O}} \mathrm{RB} / \mathrm{-RB}-\mathrm{like}$ determination. Of the 397 tubers tested from the four cvs. Atlantic (122 tubers), Yukon Gold (66 tubers), Kennebec (116 tubers), and Russet Norkotah (93 tubers), 124 $(31.2 \%)$ and $26(6.5 \%)$ were determined to be $\mathrm{PVY}^{\mathrm{O}}$ and $\mathrm{PVY}^{\mathrm{N} / \mathrm{N}: \mathrm{O} / \mathrm{NTN}}$ positive, respectively. Among the $\mathrm{PVY}$-positive samples, 3 (2.4\%), all from Russet Norkotah, tested positive for the $\mathrm{PVY}^{\mathrm{O}}-\mathrm{RB}$ isolate group, and $81(65.3 \%)$ (9 from Kennebec, 23 from Atlantic, 14 from Yukon Gold, and 35 from Russet Norkotah) for the PVYO $-\mathrm{FL}$ isolate group. Interestingly, 40 (42.3\%) (5 from Atlantic, 9 from Yukon Gold, and 26 from Russet Norkotah) of the samples failed to generate either $\mathrm{PVY}^{\mathrm{O}}$-FL- or $\mathrm{PVY}{ }^{\mathrm{O}}$-RB-specific bands, although these samples produced the common PVY band at $238 \mathrm{bp}$, suggesting the presence of a PVY ${ }^{\mathrm{O}}$-SASA-110-like or an uncharacterized $\mathrm{PVY} \mathrm{Y}^{\mathrm{O}}$ isolate in these tubers.

To test the correlation between the RT-PCR assay-determined isolate type and the pathogenicity of the virus isolates on potato plants, three randomly selected tubers that tested positive for $\mathrm{PVY}^{\mathrm{O}}$-FL-like isolates were planted together with three tubers that had tested positive for PVY ${ }^{\mathrm{O}}$-RB-like isolates. Symptomatic leaves of the resulting plants were used to inoculate virus-free Jemseg plants. By 18 dpi, isolates A6, A97, and A45 that belonged to the
PVYO-FL variant group based on the RT-PCR assay (Fig. 4) induced severe symptoms on Jemseg, whereas isolates R51, R9, and $\mathrm{R} 70$ that belonged to the PVY ${ }^{\mathrm{O}}-\mathrm{RB}$ variant group based on the RTPCR assay induced much milder symptoms on Jemseg plants (Fig. 4A).

\section{Discussion}

Viral diseases pose a continuous challenge for potato production worldwide. Stringent phytosanitary measures and seed-potato certification programs have been integrated into the production systems in many countries, including Canada and the United States, to reduce virus problems in potato crops (30). However, despite the overall success of these programs, emergence of new viruses or new virus strains has occurred even in countries where strict certification programs and rules are implemented $(4,5,13,29)$. Therefore, with unusually severe PVY-like symptoms observed on various potato cultivars in New Brunswick, Canada in 2007 by experienced CFIA field inspectors, and confirmed as part of this study as being caused by PVY, we speculated that a novel strain or infections by multiple viral strains might have occurred. This prompted urgent requests by the potato growers and inspectors to unveil the identities and properties of the causal agents. Upon completion of ELISA screening for viruses known to occur in New Brunswick, PVY was the only virus detected in the potato plants, indicating that the symptoms were probably due to PVY infection. These fields were planted with Elite 1 and 2 seed of the highest classes (1), in which current-year virus symptoms are rare; therefore, the observation of symptoms initially on foliage of one stem of each symptomatic plant, spreading subsequently to other stems and foliage, suggested that infection likely occurred and spread as a result of aphid vectors present during the growing season.

Recent progress on PVY research has depicted complicated molecular or biological diversities and evolutionary pathways of the virus. Among the known potato PVY isolates, $\mathrm{PVY}^{\mathrm{O}}$ and $\mathrm{PVY}^{\mathrm{N}}$ have been demonstrated to be parental strains $(7,18,20)$. From these strains, various recombinant substrains or isolates, including $\mathrm{PVY}^{\mathrm{N}: \mathrm{O}}\left(\mathrm{PVY}^{\mathrm{N}-\mathrm{Wi}}\right), \mathrm{Eu}-\mathrm{PVY} \mathrm{Y}^{\mathrm{NTN}}, \mathrm{PVY}^{\mathrm{NTN}-\mathrm{HN} 2}, \mathrm{PVY}^{\mathrm{NTN}-\mathrm{NW}}$, and many more have emerged $(2,4,9,13,17,19,20,23)$. Although the pathogenicity on potato of many of these isolates has not been described, some isolates may incite atypical symptoms in potato plants, as evidenced by the PVY ${ }^{\mathrm{NTN}}$ isolates discovered in the 1980s and 1990s $(12,29)$. Therefore, when isolates of PVY causing atypical symptoms were encountered in several potato cultivars in New Brunswick, this necessitated further investigation to unveil the serological, pathological, and molecular properties of these isolates. $\mathrm{PVY} \mathrm{O}^{\mathrm{O}}$ and $\mathrm{PVY} \mathrm{N}^{\mathrm{N}}$-specific antibodies revealed the serotypes of the isolates. This was followed by P1 gene- and RJ-based RTPCR genotyping. Surprisingly, all of the tests indicated that the field samples contained a PVY ${ }^{\mathrm{O}}$-like isolate exhibiting $\mathrm{PVY}^{\mathrm{O}}$ serotype and $\mathrm{PVY}^{\mathrm{O}}$ genotype. Results of a tobacco-based bioassay concurred with the assessments. Analysis of the genome sequences demonstrated that an isolate designated as $\mathrm{PVY}^{\mathrm{O}}$-FL possessed a $\mathrm{PVY}^{\mathrm{O}}$-like genome that shared $99.7 \%$ sequence identity with isolates of $\mathrm{PVY}^{\mathrm{O}}-\mathrm{Oz}$ and $97 \%$ identity with $\mathrm{PVY}^{\mathrm{O}}-139$. Like other $\mathrm{PVY}^{\mathrm{O}}$ isolates such as PVY ${ }^{\mathrm{O}}-\mathrm{Oz}$ and PV-575 $(2,10)$, PVY ${ }^{\mathrm{O}}-\mathrm{FL}$ did not induce PTNR symptoms in tubers of the sensitive potato $\mathrm{cv}$. Yukon Gold.

Results of the PVY phylogenetic analysis in this study supported previous studies on phylogenetic relationships among isolates of PVY and pm PVY evolution $(7,9,10,13,20,25)$. Moreover, the results demonstrated the existence of at least two groups of $\mathrm{PVY}$, represented by $\mathrm{PVY} \mathrm{O}_{-\mathrm{RB}} \mathrm{-139}$ and $\mathrm{PVY}^{\mathrm{O}}-\mathrm{FL} / \mathrm{-Oz} / \mathrm{-SCRI}-\mathrm{O}$. $\mathrm{PVY}^{\mathrm{O}}$-RB isolates, which induced typical, mild symptoms, and $\mathrm{PVY}^{\mathrm{O}}$-FL isolates, which incited atypical, severe symptoms on the potato cultivars evaluated, might represent two pathological groups, the former classified as a "mild" isolate and the latter as a "severe" isolate. If this hypothesis is correct, $\mathrm{PVY}^{\mathrm{O}}-\mathrm{Oz}$ and $\mathrm{PVY}^{\mathrm{O}}-$ SCRI-O should induce severe symptoms on potato plants while $\mathrm{PVY}^{\mathrm{O}}-139$ should induce mild symptoms. Because limited pathological information is available on these isolates infecting potato 


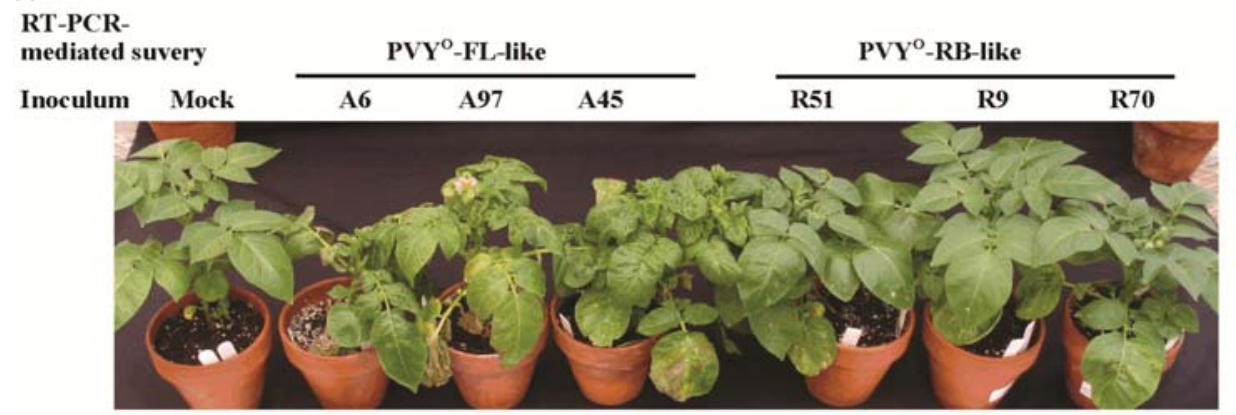

B

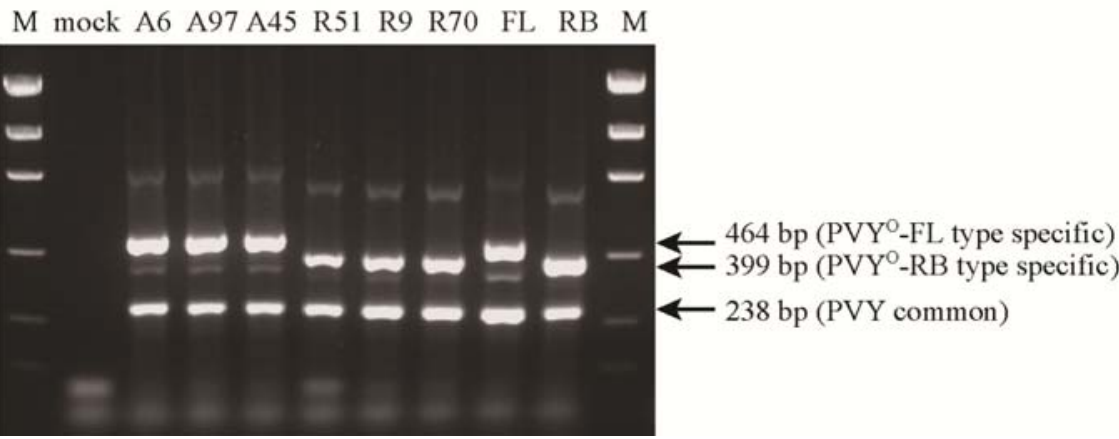

Fig. 4. Pathogenicity assays of representative Potato virus $Y$ common strain (PVYO)-FL and PVYO-RB isolates identified from field leaf samples of the potato cV. Jemseg. A minisurvey using the newly developed reverse transcription-polymerase chain reaction (RT-PCR) assay together with the P1 gene-based RT-PCR assay (17) on potato tubers collected from a field plot at the Potato Research Centre, Agriculture and Agri-Food Canada, New Brunswick, Canada, identified 81 and 3 tubers positive with PVYO FL- and PVYO-RB-like isolates, respectively. Three randomly selected PVYO-FL-like positive tubers (A6, A97, and A45) and all three PVYO-RB-like positive tubers (R51, R9, and R70) were planted in a greenhouse. The resulting plants were used for mechanical inoculation of virus-free Jemseg plants, which were then subjected to RT-PCR assay for determination of PVYO types. A, Symptoms on Jemseg 18 days post inoculation. B, RT-PCR assay results for differentiating PVYO isolate types on inoculated Jemseg plants shown in A. Lane M = DNA ladder (from top to bottom: 2,000, 1,200, 800, 400, 200, and $100 \mathrm{bp}$ ); RB = known PVYO-RB isolate, and FL = known PVYO-FL isolate (positive control treatments).

plants $(2,3,26)$, further studies with additional isolates are needed to test this hypothesis. Nevertheless, the sequence differences between the $\mathrm{PVY}{ }^{\mathrm{O}}$-FL/-Oz/-SCRI-O and $\mathrm{PVY} \mathrm{O}^{\mathrm{O}} \mathrm{RB} / \mathrm{-139}$ groups might be useful for differentiating the two groups. Using primers derived from the $5^{\prime}$ proximal end of the $\mathrm{CP}$ gene, isolates of the two groups were readily identified and differentiated in this study. When this procedure was combined with $\mathrm{P} 1$ gene-based genotyping (17) to field tuber samples, three types of $\mathrm{PVY}^{\mathrm{O}}$ were detected; namely, $\mathrm{PVY}{ }^{\mathrm{O}}-\mathrm{Oz} / \mathrm{-FL} / \mathrm{-SCRI}-\mathrm{O}, \mathrm{PVY}^{\mathrm{O}}-139 /-\mathrm{RB}$, and $\mathrm{PVY}{ }_{-}$ SASA-110-like or an uncharacterized $\mathrm{PVY}^{\mathrm{O}}$ type. The PVY ${ }^{\mathrm{O}}-\mathrm{FL} /$ -Oz/-SCRI-O type appeared to be the predominant group in potato tubers collected from four cultivars in New Brunswick. PVY isolates identified as the $\mathrm{PVY}^{\mathrm{O}}$-FL/-Oz/-SCRI-O type induced more severe symptoms than the PVY isolates identified as the PVY ${ }_{-}$ 139/-RB type when inoculated onto potato cv. Jemseg, which was consistent with the severity of symptoms exhibited by $\mathrm{PVY}{ }^{\mathrm{O}}-\mathrm{FL}$ and $\mathrm{PVY} \mathrm{Y}^{\mathrm{O}} \mathrm{RB}$ isolates, respectively. These results demonstrate the potential of $\mathrm{CP}$ gene-based genotyping for rapid identification of $\mathrm{PVY}^{\mathrm{O}}$ variants.

BLAST analysis using the $\mathrm{CP}$ gene sequence of $\mathrm{PVY} \mathrm{Y}^{\mathrm{O}} \mathrm{RB} /-139$ and $\mathrm{PVY}{ }^{\mathrm{O}}-\mathrm{FL} / \mathrm{-Oz}$ to compare with nucleotide sequences available in genetic databases demonstrated that the majority (97\%) of the sequences appeared to be $\mathrm{PVY} \mathrm{Y}^{\mathrm{O}}$-FL/-Oz (unpublished data). However, due to the lack of pathological data and descriptions associated with these available sequences, it was not possible to ascertain pathogenicity of the isolates on potato. Clearly, further studies on the biological, serological, molecular, and pathological properties of $\mathrm{PVY}^{\mathrm{O}}$ variants, including $\mathrm{PVY}^{\mathrm{O}}-\mathrm{O} 5$, which reacts to a $\mathrm{PVY}^{\mathrm{N}}$ specific antibody (11), are needed to better understand these PVY groups.

\section{Acknowledgments}

We thank K.-L. Bresson and T. Molen for technical assistance, X. Ao for participation in preliminary experiments, and Huazhong Agricultural University for financial support to B. Nie. This research was funded by Agriculture and AgriFood Canada under the Peer-Reviewed Project no. 1 (X. Nie) and by the New Brunswick Department of Agriculture and Aquaculture (M. Singh, A. Sullivan, R. Singh, and X. Nie)

\section{Literature Cited}

1. Anonymous. 1959. Seeds Act C.R.C., c.1400. Canadian Food Inspection Agency, Government of Canada, Ottawa, Ontario, Canada.

2. Baldauf, P.M., Gray, S. M., and Perry, K. L. 2006. Biological and serological properties of Potato virus $Y$ isolates in northeastern United States potato. Plant Dis. 90:559-566.

3. Barker, H., McGeachy, K. D., Toplak, N., Gruden, K., Žel, J., and Browning, I. 2009. Comparison of genome sequence of PVY isolates with biological properties. Am. J. Potato Res. 86:227-238.

4. Chikh Ali, M., Maokac, T., Natsuakib, T., and Natsuaki, K. T. 2010 PVY ${ }^{\mathrm{NTN}-\mathrm{NW}}$, a novel recombinant strain of Potato virus $Y$ predominating in potato fields in Syria. Plant Pathol. 59:31-41.

5. Crosslin, J. M., Hamm, P. B., Hane, D. C., Jaeger, J., Brown, C. R., Shiel, P. J., Berger, P. H., and Thornton, R .E. 2006. The occurrence of PVYO, $\mathrm{PVY}^{\mathrm{N}}$, and PVYN:O strains of Potato virus $Y$ in certified potato seed lot trials in Washington and Oregon. Plant Dis. 90:1102-1105.

6. Ellis, P., Stace-Smith, R., and de Villiers, G. 1997. Identification and geographical distribution of serotypes of potato virus Y. Plant Dis. 81:481-484.

7. Glais, L., Tribodet, M., and Kerlan C. 2002. Genomic variability in Potato potyvirus $Y$ (PVY): evidence that $\mathrm{PVY}^{\mathrm{NW}}$ and $\mathrm{PVY} \mathrm{YNN}^{\mathrm{NTN}}$ variants are single to multiple recombinants between $\mathrm{PVY}^{\mathrm{O}}$ and $\mathrm{PVY}^{\mathrm{N}}$ isolates. Arch. Virol. 147:363-378.

8. Hane, D. C., and Hamm, P. B. 1999. Effects of seedborne Potato virus $Y$ infection in two potato cultivars expressing mild disease symptoms. Plant Dis. 83:43-45.

9. Hu, X., He, C., Xiao, Y., Xiong, X., and Nie, X. 2009. Molecular characterization and detection of recombinant isolates of Potato virus $Y$ from China. Arch. Virol. 154:1303-1312.

10. Hu, X., Meacham, T., Ewing, L., Gray, S. M., and Karasev, A. V. 2009. A novel recombinant strain of Potato virus $Y$ suggests a new viral genetic determinant of vein necrosis in tobacco. Virus Res. 143:68-76.

11. Karasev, A. V., Nikolaeva, O. V., Hu, X., Sielaff, Z., Whitworth, J., Lorenzen, J. H., and Gray, S. M. 2010. Serological properties of ordinary and necrotic isolates of Potato virus Y: a case study of $\mathrm{PVY}^{\mathrm{N}}$ misidentification. Am. J. Potato Res. 87:1-9. 
12. Le Romancer, M., Kerlan, C., and Nedellec, M. 1994. Biological characterization of various geographical isolates of potato virus $\mathrm{Y}$ inducing superficial necrosis on potato tubers. Plant Pathol. 43:138-144.

13. Lorenzen, J., Nolte, P., Martin, D., Pasche, J. S., and Gudmestad, N. C. 2008. NE-11 represents a new strain variant class of Potato virus Y. Arch. Virol. 153:517-525.

14. Lorenzen, J. H., Piche, L. M., Gudmestad, N. C., Meacham, T., and Shiel, P. 2006. A multiplex PCR assay to characterize Potato virus $Y$ isolates and identify strain mixtures. Plant Dis. 90:935-940.

15. McDonald, J. G. 1984. Viruses associated with mosaic symptoms in Russet Burbank potato. Can. J. Plant Pathol. 6:224-226.

16. Mohapatra, S. S., Poole, R. J., and Dhindsa, R. S. 1987. Changes in protein patterns and translatable messenger RNA populations during cold acclimation of alfalfa. Plant Physiol. 84:1172-1176.

17. Nie, X., and Singh, R. P. 2002. A new approach for the simultaneous differentiation of biological and geographical strains of Potato virus $Y$ by uniplex and multiplex RT-PCR. J. Virol. Methods 104:40-54

18. Nie, X., and Singh, R. P. 2003. Evolution of North American PVY ${ }^{\mathrm{NTN}}$ strain $\mathrm{Tu} 660$ from local $\mathrm{PVY}^{\mathrm{N}}$ by mutation rather than recombination. Virus Genes 26:39-47.

19. Nie, X., and Singh, R. P. 2003. Specific differentiation of recombinant PVYN:O and PVY ${ }^{\text {NTN }}$ strains by multiplex RT-PCR. J. Virol. Methods 113:69-77.

20. Nie, X., Singh, R. P., and Singh, M. 2004. Molecular and pathological characterization of N:O isolates of the Potato virus $Y$ from Manitoba, Canada. Can. J. Plant Pathol. 26:573-583.

21. Nolte, P. 1997. Why a significant increase in virus and methods of control. Pages 24-26 in: Proc. 16th Annu. Natl. Potato Council Seed Semin. Traverse City, MI.

22. Nolte, P., Whitworth, J. L., Thornton, M. K., and McIntosh, C. S. 2004. Effect of seedborne Potato virus $Y$ on performance of Russet Burbank, Russet Norkotah, and Shepody potato. Plant Dis. 88:248-252.

23. Piche, L. M., Singh, R. P., Nie, X., and Gudmestad, N. C. 2004. Diversity among Potato virus $Y$ isolates obtained from potatoes grown in the United
States. Phytopathology 94:1368-1375.

24. Riechmann, J. L., Laín, S., and García, J. A. 1992. Highlights and prospects of potyvirus molecular biology. J. Gen. Virol. 73:1-16.

25. Schubert, J., Fomitcheva, V., and Sztangret-Wisniewski, J. 2007. Differentiation of Potato virus $Y$ using improved sets of diagnostic PCR-primers. J. Virol. Methods 140:66-74.

26. Singh, M., and Singh, R. P. 1996. Nucleotide sequence and genome organization of a Canadian isolate of the common strain of potato virus $\mathrm{Y}\left(\mathrm{PVY} \mathrm{Y}^{\mathrm{O}}\right)$ Can. J. Plant Pathol.18:209-214.

27. Singh, R. P., and Boiteau, G. 1984. Necrotic lesion host for potato virus Y useful in epidemiological studies. Plant Dis. 68:779-781.

28. Singh, R. P., McLaren, D. L., Nie, X, and Singh, M. 2003. Possible escape of a recombinant isolate of Potato virus $Y$ by serological indexing and methods of its detection. Plant Dis. 87:679-685.

29. Singh, R. P., Valkonen, J. P. T., Gray, S. M., Boonham, N., Jones, R. A. C. Kerlan, C., and Schubert, J. 2008. Discussion paper: the naming of Potato virus $Y$ strains infecting potato. Arch. Virol. 153:1-13.

30. Slack, S. A., and Singh R. P. 1998. Control of viruses affecting potatoes through seed potato certification programs. In: Plant Virus Disease Control. A. Hadidi, R. K. Khetarpal, and H. Koganezawa, eds. American Phytopathological Society, St. Paul, MN

31. Sturz, A. V., Diamond, J. F., and Stewart, J. G. 1997. Evaluation of mosaic symptom expression as an indirect measure of the incidence of $\mathrm{PVY}^{\mathrm{O}}$ in potato cv. Shepody. Can. J. Plant Pathol. 19:145-148.

32. Tamura, K., Dudley, J., Nei, M., and Kumar, S. 2007. MEGA4: Molecular Evolutionary Genetics Analysis (MEGA) software, version 4.0. Mol. Biol. Evol. 24:1596-1599.

33. Valkonen, J. P. T., Slack, S. A., and Plaisted, R. L. 1994. Use of the virus strain group concept to characterize the resistance to $\mathrm{PVX}$ and $\mathrm{PVY} \mathrm{Y}^{\mathrm{O}}$ in the potato cv. Allegany. Am. Potato J. 71:507-516.

34. Whitworth, J. L., Nolte, P., McIntosh, C., and Davidson, R. 2006. Effect of Potato virus $Y$ on yield of three potato cultivars grown under different nitrogen levels. Plant Dis. 90:73-76. 